\title{
Legal aspects of contraceptive implants
}

\section{Sam Rowlands}

\section{Introduction}

Litigation can be seen as a reflection of medical error and harm to patients. Studying litigation may reveal trends from which lessons can be learned, leading to improvements in patient safety. ${ }^{1}$ The threat of litigation may be of some value in increasing investment in safety. ${ }^{2}$ An alternative to costly litigation is a no-fault compensation system, as was established in New Zealand in $1974 .^{3}$ In this system, doctors of good standing who generally perform well are not punished by being subjected to an adversarial legal system. Members of the public who are harmed by errors receive fair, timely compensation. However, such a system may result in less accountability. ${ }^{3}$

This article aims to review some legal aspects of contraceptive implants. Three types of incident repeatedly feature in legal cases in a range of countries: non-insertion, deep insertion and nerve injury.

\section{Background}

After research on contraceptive implants from 1966 onwards, a six-capsule delivery system with a lifespan of 5 years was ready for clinical studies by 1974 . Multinational Phase III trials of this system, Norplant ${ }^{\circledR}$, followed. The first country to grant marketing authorisation was Finland in 1983. By 1990, more than half a million women had used Norplant in 17 countries where it had marketing authorisation and in a further 29 countries where pre-introductory trials had taken place.

In the UK the manufacturer of Norplant, Roussel, devised a cascade training programme: eight key clinicians went to Jakarta, Indonesia, for a week in April 1993 to practise insertion, removal and counselling techniques. On their return, these eight key instructors trained key health professionals in 35 training centres; this second tier then provided training in their regions for general practitioners (GPs), family planning doctors and gynaecologists. The product was launched in the UK in October 1993. Within 14 months, around 3600 doctors had completed the practical training for Norplant insertion. Many of these doctors were GPs without family planning training. After an initial surge of enthusiasm, many did not persist with the work and in particular did not train to do removals. There was also a reluctance by many GPs to do implant procedures due to lack of an item of service fee. 4

In 1995, a UK group action was mounted against the manufacturer of Norplant. A firm of solicitors in Nottingham co-ordinated cases from 34 different firms. It was the first attempt to bring a case of a prescription-only medicine as an allegedly defective product under the Consumer Protection Act 1987.5 There was an initial allegation that the product was introduced hastily with a substandard training programme, but expert evidence did not support this. The main claim, by 275 women, was for a

J Fam Plann Reprod Health Care 2010; 36(4): 243-248

(Accepted 20 August 2010)

Institute of Clinical Education, Warwick Medical School, University of Warwick, Coventry, UK

Sam Rowlands, LLM, MD, Honorary Associate Professor

Correspondence to: Dr Sam Rowlands, Institute of Clinical Education, Warwick Medical School, Gibbet Hill Campus, University of Warwick, Coventry CV4 7AL, UK.

E-mail: sam.rowlands@warwick.ac.uk

\section{Key message points}

- There has been litigation in relation to the three types of harm associated with contraceptive implants: noninsertion, deep insertion and nerve injury.

- Recommendations for safe clinical practice can be derived from analysis of legal cases and published case reports.

- Nerve injury has invariably been caused by clinicians without upper limb surgical skills attempting difficult removals.

- The launch of the updated single-rod implant (Nexplanon ${ }^{\circledR}$ ) may offer the best possibility for harm reduction.

- Litigation in relation to side effects can lead to the withdrawal of safe and effective contraceptive products, so reducing choice for women.

range of possible levonorgestrel-related side effects and difficulties with removal. The allegation was that the product information did not fairly represent the severity of the adverse effects associated with the product. The individual claims for damages were small. Legal aid had been granted to 189 of these women. The case collapsed in 1999 when the Legal Aid Board, as it then was, withdrew funding, having decided that the chances of success did not justify the high cost of a trial. ${ }^{6}$ The remainder of the women, who were self-funding, decided to withdraw at this point. Exchange of expert evidence had revealed that the effects of the product were within the predicted range and fairly summarised, so that there was no defect in the product.

Two months later, the manufacturer decided to discontinue the sale of Norplant in the UK on commercial grounds. The number of women using the product had reached only 55000 (among 6 million users worldwide), the manufacturer having spent $£ 3$ million on doctor training alone. A 'boom and bust' phenomenon, ${ }^{7}$ which had been seen in the USA, characterised by a degree of overpromotion initially followed by adverse reports in the media 8 and litigation, also occurred to some extent in the UK.

However, the situation was different in the USA. In the mid-1990s, when 1 million women were using Norplant, ${ }^{9}$ 36000 women commenced a class action against the manufacturer. Allegations of harm fell into three broad categories: ${ }^{9}$

- removal difficulties

- possible levonorgestrel side effects

- silastic-related claims including autoimmune disorders alleged to be related to the silicone elastomer tubing.

Despite the threatened litigation, Wyeth-Ayerst Laboratories decided to continue marketing the product. Even with aggressive recruitment by personal injury lawyers, only approximately $5 \%$ of all Norplant users joined lawsuits, and the courts denied class action status for the plaintiffs. ${ }^{10}$ The vast majority of the 14000 cases in the USA were dismissed, and eventually only a small number were settled out of court for an average of $\$ 1400$ each.

In the UK, Implanon ${ }^{\circledR}$, a single-rod implant containing etonogestrel, was launched by Organon Laboratories in a more measured fashion than Norplant had been. Implanon has a 3-year lifespan. It is a semi-rigid rod, making it more robust and quicker and easier to insert and remove than Norplant. Unlike Norplant, it is amenable to the 'pop-out' removal technique. The launch in 1999 was less of a challenge than that of Norplant because there was already 
a clinical workforce in place with experience of implant techniques. Initial training was confined to contraception specialists.

The Implanon applicator has recently been redesigned and the product will shortly be relaunched as Nexplanon ${ }^{\circledR}$ by the current manufacturer, MSD, with a view to reducing the risks of non-insertion and deep insertion. ${ }^{11}$ The new implant rod will be radio-opaque to aid imaging of nonpalpable implants. ${ }^{12}$

The following three types of harm associated with Implanon are based on global experience over 11 years with the original applicator design. Any clinician who inserts implants should be aware of these potential problems.

\section{Non-insertion}

Clinicians who act as expert witnesses in relation to legal cases have seen a substantial number of cases of litigation on account of non-insertion of Implanon, usually presenting with an unexpected pregnancy: the implant cannot be palpated, is not seen on ultrasound scan and etonogestrel is undetectable in the serum. Non-insertion with pre-loaded Implanon, unrecognised at the time, was not reported in the pre-launch trials. ${ }^{13}$ Clinical trials conducted during the development of Implanon covered 4103 woman-years and reported no pregnancies. ${ }^{14}$ True method failures might have been predicted after more extensive use, but not failure to have placed a device in the arm at the end of the insertion procedure.

In Australia, after national post-marketing surveillance picked up 84 cases of non-insertion, a risk management process was invoked. ${ }^{15}$ In France, 30 cases of non-insertion were reported to regional pharmacovigilance centres. ${ }^{16}$ Cases of non-insertion have also been reported in the British literature. ${ }^{17,18}$ Spontaneous reporting to the Medicines and Healthcare products Regulatory Agency (MHRA) ${ }^{19}$ recorded 535 unintended pregnancies by 27 May 2010, but the proportion of these due to non-insertion is not known.

Implanon was launched in The Netherlands in 1999. In 2002, a class action against Organon and 13 GPs was brought by 15 Dutch women who had become pregnant following non-insertion. Ten of these women continued their pregnancies and delivered, four had abortions and one miscarried. At the trial in 2005, Organon and/or the doctors were found liable for the unintended pregnancies. The judge concluded that both the company and the doctors should pay damages unless either could bring further evidence. In 2007, at appeal with new evidence presented, the decision was reversed and the burden of proof transferred to the women. ${ }^{20}$ The women were told that in order to succeed in court they would have to prove that their doctor had failed to check: (a) that the implant was present in the needle, (b) that it was no longer in the needle after the procedure and (c) that it could be palpated in the arm after the procedure. This judgment effectively ended the class action. However, individual claims had been settled out of court in favour of Dutch claimants. In Britain, the amount of damages paid out for wrongful conception is small because of the limiting effect of the McFarlane case. In McFarlane v Tayside Health Board, it was held by a majority of Law Lords that the McFarlanes could recover damages for the wife's pain and distress in pregnancy and labour following her husband's failed vasectomy, but not for the cost of raising their daughter. ${ }^{21}$ However, in The Netherlands, damages can include the cost of the upbringing of the child. Award of this higher level of damages has also been reported in Australia. ${ }^{22}$

In an attempt to reduce the chance of a non-insertion, the company reinforced pre-existing advice in a letter to clinicians dated June 2001, stressing that:
- the presence of the implant must be visually verified before insertion is performed

- the introducer should be held with the needle upwards at all times between removing the needle shield and the insertion

- the obturator should be retracted to check that the needle is empty after insertion

- the implant should be carefully palpated in the arm after insertion.

The manufacturer also modified the end of the obturator in 2004; it added a groove in its tip so that there can be no confusion with the appearance of an implant still in the needle after insertion. However, this does not confirm that the implant has been inserted successfully.

Despite revised guidance and publication of case reports of this problem, sporadic cases of non-insertion have continued to be seen in clinical and legal practice.

\section{Deep insertion}

Contraceptive implants should be inserted into the subdermal plane. The problem of difficult removals due to deep insertion was first seen with Norplant; it was found that $1 \%$ of removals were complicated because the implant was 'embedded'.23 Deep insertion is thought to be associated with the insertion technique rather than migration of a properly inserted implant. ${ }^{18,24,25}$ It has been suggested that with Implanon the implant may be pushed out of the applicator, rather than using the correct technique of withdrawing the outer casing, keeping the obturator fixed; the implant may then take the path of least resistance. ${ }^{24}$ In some cases, the proximal end of the implant is seen to be deeper than the distal end, suggesting a downward slant of the applicator at the time of insertion. ${ }^{18}$

Deep insertion may be more likely to occur in thin women with scant subcutaneous tissue. 25 Weight gain subsequent to insertion may make an implant less easy to palpate and therefore more difficult to remove. ${ }^{26}$

It is not thought that a rod can migrate significantly in the arm unless it is placed subcutaneously. 27 Migration of up to $5 \mathrm{~cm}$ has been reported but is rare. ${ }^{28}$ It seems unlikely that implants can penetrate fascia spontaneously. However, a degree of migration has been reported when Implanon implants have been inserted into the wound immediately after removal of Norplant. 25,29

Since 2003, there have been several case reports and case series of impalpable Implanons and suggestions as to how best to retrieve these. $18,24,29,30$ If an implant cannot be palpated when removal is being considered, imaging may assist. Implanon does not show up reliably on X-rays or computed tomography (CT) scans. An ultrasound or magnetic resonance imaging (MRI) scan will usually show the position of the implant. ${ }^{31}$ Fluoroscopy has also been used by interventional radiologists. ${ }^{32}$ The consensus is that there must be accurate localisation of the impalpable implant using a high-resolution linear array ultrasound transducer before any incision for its removal is made. ${ }^{25}$

The concept of specialist centres for predictably difficult removals had evolved in the Norplant era. ${ }^{33}$ UK recommended practice was further reinforced by experience in the USA showing that real-time ultrasound guidance was a very useful way of localising Norplant capsules $^{34}$ and that this was possible in a non-hospital setting. With Implanon, further experience has been gained and the number of specialist centres has expanded. ${ }^{35} \mathrm{MSD}$ now provides a training course for expert removers in the localisation of deep Implanons and the identification of adjacent neurovascular structures; this course was developed in order to minimise the risk of injury to these structures. The course comprises training on the anatomy 


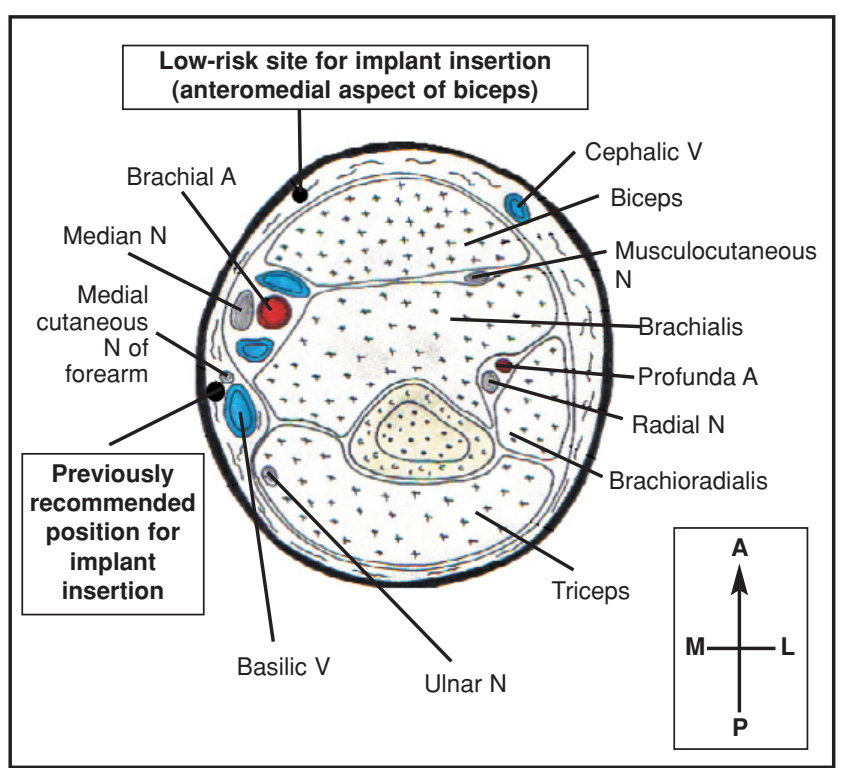

Figure 1 Cross-sectional anatomy of the arm at the level $7 \mathrm{~cm}$ proximal to the medial epicondyle, showing the previously recommended position for implant insertion and Bragg et al.'s suggested 'low-risk' position. A, artery; N, nerve; V, vein, Orientation: A, anterior; L, lateral; M, medial; P, posterior. Adapted from a figure by Thomas $\mathrm{W} H$ Bragg, reproduced with permission from Bragg TWH, et al., Implantable contraceptive devices: primum non nocere. J Fam Plann Reprod Health Care 2006; 32: 190-192

of the arm, on the use of ultrasound for imaging the upper arm and on surgical techniques for complex implant removal (MSD, personal communication, 29 July 2010).

The most common abnormal positioning of implants is deep in subcutaneous fat. The next most common site is overlying or within the biceps muscle, 18,36 while placement within the triceps muscle has also been described. ${ }^{25}$ Deep implants may be located near or within the neurovascular bundle. 37,38

There have been many cases of deep placement of implants, some of which have resulted in litigation. The cases sometimes involve two or more attempts at removal. In some cases regional experts fail to remove the implant. In such cases, the women are usually referred to a surgeon who may be a general surgeon, a plastic surgeon or an orthopaedic surgeon. Generally the surgeon will do the removal under general anaesthesia with a fairly generous longitudinal incision. With a few exceptions, surgeons appear to have little difficulty in finding and removing an implant under these conditions. As far as the author is aware, injury to neurovascular structures has not been seen when removal is performed by a surgeon. Legal cases of failed removals with subsequent surgical removal under general anaesthesia have been settled out of court in Britain. For example, in 2005, a claimant was awarded $£ 8500$ in damages to be paid by Sefton Primary Care Trust. ${ }^{39}$ In France there have been similar experiences, with medical defence insurance covering the costs. 38

As a result of the above considerations, a widely adopted protocol is that if an implant cannot be palpated easily, a more experienced member of the local team should attempt removal. Implants that are completely impalpable should be referred to a regional centre where removal of non-palpable implants using techniques developed by leading experts 40 is almost always successful. Nevertheless, following complex removal procedures there is potential for neurovascular injury, infection and scar or keloid formation. Regional centres that demonstrate that implants are close to vital structures may decide to refer onward to surgeons or interventional radiologists. 40

\section{Nerve injury}

The positioning of implants in the body had been given a considerable amount of thought before Norplant was launched. Sites such as the abdomen are not favoured for non-biodegradable implants as migration is prone to occur. The arm is preferred because of the minimal thickness of subcutaneous tissue; the disadvantage is that vital structures are nearer the surface. The Summer 2000 issue of the 'Implanon Newsletter', produced by Organon for clinicians trained to insert Implanon, reiterated the rationale for the site of insertion. Placement in the groove between the biceps and triceps muscles was recommended to limit the chance of migration, but with a warning of the presence of the neurovascular bundle just beneath the fascia. A warning was also given of the not uncommon variation in the position and branching of the brachial artery. Careful inspection and palpation of the arm prior to insertion was advised.

The recommended site for both Norplant and Implanon used to be in the groove, $6-8 \mathrm{~cm}$ above the elbow crease. The neurovascular bundle (comprising the brachial artery, basilic vein, median nerve, ulnar nerve and medial cutaneous nerve of the forearm) is situated a few millimetres deep to the fascia at this point (Figure 1). For reasons that are not clear, damage to the neurovascular bundle is usually confined to nerves. Vascular injury has been reported, ${ }^{41}$ but is rare.

More than a decade ago a case of ulnar nerve palsy in association with insertion of Norplant ${ }^{42}$ was reported. There is one other report relating to injury to a nerve at the time of Norplant insertion. This involved sensory loss in the distribution of the medial cutaneous nerve of the forearm. ${ }^{43}$ In general, however, nerve injury occurs in association with implant removal.

In 1995, a paper from the USA highlighted the possibility of damaging nerves during difficult Norplant removals and related this to the recommended insertion site. ${ }^{44}$ Although the authors had not themselves seen the cases, they had heard of two severe injuries in other parts of the USA. The first was of wrist drop and atrophy of the hand muscles. The second was such a severe injury that amputation of the arm was necessary. A Spanish follow-up study described transient paraesthesiae in the hands of three women in a series of 372 removals, but the exact distribution of sensory disturbance in their hands was not specified. ${ }^{45}$

In the following section of this article, three anonymised examples of legal cases are used from the author's experience as an expert witness.

\section{Medial cutaneous nerve of the forearm}

In 2001, a case of a neuropathy occurring after removal of Norplant was reported. ${ }^{46}$ In 2006, a further case of nerve damage relating to removal of Implanon was reported from Austria. ${ }^{47}$ The nerve was partially severed and needed microsurgical repair. The authors of both reports commented on the vulnerability of the site advised by the company with respect to the nerves and vessels.

Legal Case 1
A GP tried to remove an impalpable Implanon, sited in an area
previously used for Norplant ${ }^{\circledR}$. At a second unsuccessful attempt
at removal of the implant, the medial cutaneous nerve of the
forearm was damaged. The claimant subsequently needed
neurolysis (division of perineural adhesions) by an upper limb
surgeon; the implant was not found at this operation. The
claimant's residual neuropraxia was slow to improve. The implant
was located and removed 3 years later when the claimant wanted
to conceive.




\section{Median nerve}

In 2006, two cases of sensory disturbance, possibly in the distribution of the median nerve during or immediately after removal of Implanon, were reported. ${ }^{48}$ Both women were of slim build. It was thought that the adverse effect was merely from the local anaesthetic and so was transient. But the author emphasised how it was somewhat perverse to choose an insertion site so close to neurovascular structures.

\section{Legal Case 2}

A GP failed to remove an Implanon ${ }^{\circledR}$. A local gynaecologist later also failed to remove the Implanon. A third unsuccessful removal attempt was made by a gynaecologist in a tertiary hospital under general anaesthesia. During the last operation the median nerve was damaged. The claimant subsequently needed neurolysis. The implant was not found.

\section{Ulnar nerve}

In 1998, two cases of ulnar nerve injury were described with Norplant. The first was in a soldier from the USA who was serving in Germany. ${ }^{49}$ At operation, the nerve was intact but had an 'hour-glass' constriction. Neurolysis was performed 2 months after the injury. There was residual neurological deficit 6 months postoperatively. In the second case, Norplant was removed in the USA; the implant was situated low down quite near to the elbow. 50 The woman reported sensory symptoms as soon as local anaesthesia was infiltrated into the site. Symptoms were continuing to resolve when the woman was seen for the last time.

In 2005, two ulnar nerve lesions were reported from France ${ }^{51}$ Both women were of slim build with body mass indices of 18 and 19 respectively. In the first case, Implanon had penetrated the perineurium and a microsurgical procedure was needed to remove the implant. In the second case, because of persistent sensory disturbance after removal of Implanon, neurolysis was needed.

In 2006, a case of ulnar nerve contusion was reported after Norplant removal in the UK. ${ }^{52}$ The woman had previously had a difficult removal at the same time as a further Norplant insertion. This time the GP was unable to remove any of the capsules. The woman had a subsequent difficult removal at a family planning centre and experienced electric shock-like symptoms during the procedure but did not mention them at the time. She then developed numbness. Two days later plastic surgeons explored the wound to find the ulnar nerve intact but contused. The woman made a slow recovery. The authors expressed concern about the recommended insertion site.

In the USA, a woman who suffered ulnar nerve injury at the time of Norplant removal by a nurse practitioner was awarded $\$ 2.25$ million in damages. ${ }^{53}$

\section{Legal Case 3}

The ulnar nerve was damaged both at insertion and again on removal of Implanon ${ }^{\circledR}$ performed by a GP. A complex regional pain syndrome ensued and the claimant needed an exploratory operation at which nerve repair and neurolysis were performed.

\section{Spontaneous reporting of adverse events in the UK}

The MHRA's online listing of spontaneous reports on etonogestrel implants was last updated on 27 May 2010,54 giving 11 years' experience of Implanon. Reported adverse reactions suggesting neurological disturbances are shown in Table 1.

\section{Change in insertion site recommended by the manufacturer}

In response to repeated reports of nerve injury, in June 2007 the manufacturer revised the Summary of Product
Characteristics, deleting reference to the biceps/triceps groove. This revision was accepted by the MHRA in August 2007. A letter dated April 2008 was sent out to all health professionals known to be inserting Implanon in July 2008 (Schering-Plough, personal communication, 5 June 2009). The recommended site was changed to above the medial epicondyle of the humerus, which is behind the groove. An announcement to this effect was made in the October 2008 issue of the Journal of Family Planning and Reproductive Health Care (page 272).

Although nerve damage is a rare complication of contraceptive implants, it is clearly a serious one. It has been agreed that insertion immediately over the biceps/triceps groove is unwise.

\section{Discussion}

Implant litigation has generally been of two types. Following the launch of Norplant and Implanon, there was litigation in several countries in relation to adverse effects. It has been shown that class actions tend to exaggerate the incidence of a device's side effects. ${ }^{55}$ Litigation was not usually successful for the claimants, unless the company decided to settle for pragmatic business reasons, as in the USA. However, litigation damaged confidence in the products and was responsible for the demise of Norplant in the UK.

The second type of litigation has been in relation to non-insertion, deep insertion and nerve injury. The first two of these can be linked to the design of the applicator system, so that it should prove possible to increase safety by design improvement. ${ }^{15}$ The potential for reducing harm by training or re-training is probably limited. ${ }^{15}$ The harm caused by nerve damage is potentially the most severe. It is tragic when a healthy young woman suffers long-term and in some cases permanent injury through using a method of contraception. Legal cases highlight the type of harm that may arise and encourage learning in order to improve the safety of this highly effective long-acting reversible contraceptive method.

It is important to palpate the arm after insertion and to record in the notes that this has been done. In some legal cases, clinicians have palpated the insertion site and convinced themselves they could feel the implant. They have asked the client to palpate the insertion site and as they had never previously felt an implant and possibly because of some local swelling, clients although not convinced agreed that the implant could be felt. Another check might therefore be for the client to be told to have a careful feel after removing the dressing and to report any doubts then.

Deep insertion predisposes to injury to the neurovascular bundle. It has been suggested that there

Table 1 Adverse reactions reported to the Medicines and Healthcare products Regulatory Agency (MHRA) relating to etonogestrel implants during the period 1999-2010

\begin{tabular}{lc}
\hline Adverse reaction & $\boldsymbol{n}$ \\
\hline Implant site paraesthesia & 2 \\
Nerve injury not elsewhere classified & 1 \\
Median nerve injury & 1 \\
Ulnar nerve injury & 5 \\
Carpal tunnel syndrome & 1 \\
Burning sensation & 1 \\
Paraesthesia & 25 \\
Hypoaesthesia & 11 \\
Neuralgia & 4 \\
Sensory loss & 1 \\
Sensory disturbance & 1 \\
Total & 53 \\
\hline
\end{tabular}


Box 1: Recommendations for contraceptive implant insertion

- Avoid the biceps/triceps groove.

- Palpate for the brachial artery and, if palpable, keep at least $1 \mathrm{~cm}$ away from it.

- Once the skin is punctured by the needle tip, advance the needle parallel to the skin surface, keeping superficial by lifting the skin with the tip of the needle.

- Palpate the inserted implant through the skin and ensure that the woman does so too.

Box 2: Recommendations for contraceptive implant removal

- Palpate the rod and make an assessment of the likely ease of removal.

- Always work within your own competence (don't just 'have a go'). Refer to a more experienced clinician if necessary.

- Palpate for the brachial artery.

- Do not attempt removal if the rod is close to the brachial artery.

- If there is any indication of sensory disturbance, abandon the procedure.

should be feedback to the person who did the insertion when this occurs and, if there are repeat occurrences, to the inserting clinician's clinical supervisor. 35,40

The other element in nerve injury is the optimal insertion site. Surgeons such as Bragg recommend going anterior to the biceps/triceps groove, while the manufacturer recommends going posterior to the groove; there is no evidence that one site is better than the other. But insertion over the groove is unwise and surgically trained authors have commented in no uncertain terms on this. ${ }^{47,52}$ The brachial artery can be used as a marker for the neurovascular bundle; if it is palpable, the insertion site should be a safe distance away from it. Clinicians need to change their practice to avoid the groove. This should, in most cases, prevent the risk of neurovascular injury during difficult removals.

Regional experts themselves need to know their limitations. These experts may have surgical experience, but this is usually of a gynaecological nature. It has become accepted that regional experts do operations with retractors, forceps and dissection. This may not always be in clients' best interests. There should be a lower threshold for referral to upper limb surgeons or interventional radiologists, preferably those who have developed a special interest in implants and their localisation. It has been suggested that some deep implants that are beyond their lifespan may be best left in situ rather than being subjected to a procedure predicted to be risky. ${ }^{29}$

\section{Recommendations for safe clinical practice}

In conclusion, reflecting on cases that have been reported in the literature or that have been the subject of litigation, the following recommendations are presented in relation to insertion and removal of contraceptive implants (Boxes 1 and 2). The improvements in the design of the new product, Nexplanon, which will be launched towards the end of 2010, may reasonably be assumed to reduce the risks of both non-insertion and deep insertion. However, it may not be possible to eliminate them; deep insertion has been seen in preliminary experience with Nexplanon. ${ }^{12}$

\section{Statements on funding and competing interests} Funding None identified.

Competing interests The author has received payment for delivering training sessions for both Norplant, and Implanon, and has had expenses paid for attending scientific congresses by companies marketing these implants. The author receives fees for acting as an expert witness.
Editor's note

Interested readers should also see Diana Mansour's Commentary article on Nexplanon ${ }^{\circledR}$ (page 187) and the article on a risk management approach to the design of contraceptive implants (page 191) by Rowlands et al. in this issue of the Journal.

\section{References}

1 Vincent C. Patient Safety. Edinburgh, UK: Churchill Livingstone, 2006.

2 Merry AF. How does the law recognize and deal with medical errors? J R Soc Med 2009; 102: 265-271.

3 Bismark M, Paterson R. No-fault compensation in New Zealand: harmonizing injury compensation, provider accountability, and patient safety. Health Aff 2006; 25: 278-283.

4 Waters A. GPs advised to stop inserting Norplant. GP 1995; 29 September 1995

5 Rowlands S. Protecting new contraceptive methods. Contraceptive Education Bulletin 1997; Winter 1997: 5.

6 Robins J. Norplant case collapses as tobacco multi-party action trips up in court. Law Society Gazette 1999; 10 February 1999.

7 Boonstra H, Duran V, Gamble VN, Blumenthal P, Dominguez L, Pies C. The 'boom and bust' phenomenon: the hopes, dreams, and broken promises of the contraceptive revolution. Contraception 2000; 61: 9-25.

8 Entwistle VA, Watt IS, Johnson F. The case of Norplant as an example of media coverage over the life of a new health technology. Lancet 2000; 355: 1633-1636.

9 Committee on Contraceptive Research and Development. Contraceptive Research, Introduction, and Use: Lessons from Norplant. Washington, DC: Institute of Medicine, 1998.

10 Association of Reproductive Health Professionals. Health Matters Fact Sheet. The Single Rod Contraceptive Implant. 2008. http://www.arhp.org/Publications-and-Resources/ Patient-Resources/fact-sheets/single-rod [Accessed 22 July 2010].

11 Mansour D. Nexplanon ${ }^{\circledR}$ : what Implanon ${ }^{\circledR}$ did next. J Fam Plann Reprod Health Care 2010; 36: 187-189.

12 Mansour D, Mommers E, Teede H, Sollie-Eriksen B, Graesslin $\mathrm{O}$, Ahrendt $\mathrm{H}-\mathrm{J}$, et al. Clinician satisfaction and insertion characteristics of a new applicator to insert radiopaque Implanon: an open-label, noncontrolled, multicenter trial. Contraception 2010; 82: 243-249.

13 Mascarenhas L. Insertion and removal of Implanon ${ }^{\circledR}$. Contraception 1998; 58(Suppl. 6): 79S-83S

14 Croxatto HB, Mäkäräinen L. The pharmacodynamics and efficacy of Implanon. Contraception 1998; 58: 91S-97S.

15 Rowlands S, Sujan MA, Cooke M. Risk management aspects of contraceptive implants. J Fam Plann Reprod Health Care 2010; 36: 191-195.

16 Bensouda-Grimaldi L, Jonville-Bera AP, Beau-Salinas F, Llabres S, Autret-Leca E. Insertion problems, removal problems and contraception failures with Implanon ${ }^{\circledR}$ [in French]. Gynecol Obstet Fertil 2005; 33: 986-990.

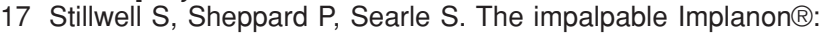
a case report. J Fam Plann Reprod Health Care 2003; 29: 156-157.

18 Singh M, Mansour D, Richardson D. Location and removal of non-palpable Implanon $\AA$ implants with the aid of ultrasound guidance. J Fam Plann Reprod Health Care 2006; 32: 153-156.

19 Medicines and Healthcare products Regulatory Agency (MHRA). The Yellow Card Scheme - Collecting Information on Adverse Drug Reactions. http://www.mhra.gov.uk/Safety information/Reportingsafetyproblems/Medicines/index.htm\#1 [Accessed 17 July 2010].

20 Court imposes the burden of proof on the women in case of Implanon unintended pregnancies [in Dutch]. The Legal Daily, 28 August 2007. http://juridischdagblad.nl/content/view/5549/ 53/ [Accessed 17 July 2009].

21 McFarlane $v$ Tayside Health Board [2000] 2 AC 59, MLC 0127 , HL. 2000 .

22 Wood M, Price S. Lawsuits flying over 'failed' contraceptive. Sydney Morning Herald, 13 February 2005.

23 Dunson TR, Amatya RN, Kreuger SL. Complications and risk factors associated with the removal of Norplant implants. Obstet Gynecol 1995; 85: 543-547.

24 Walling M. How to remove impalpable Implanon ${ }^{\circledR}$ implants. J Fam Plann Reprod Health Care 2005; 31: 320-321.

25 Mansour D, Fraser IS, Walling M, Glenn D, Graesslin O, Egarter C, et al. Methods of accurate localisation of nonpalpable subdermal contraceptive implants. J Fam Plann Reprod Health Care 2008; 34: 9-12. 
26 Navani M, Robinson C. Clinical challenge with Implanon ${ }^{\circledR}$ removal: a case report. J Fam Plann Reprod Health Care 2005; 31: 161-162.

27 Ismail H, Mansour D, Singh M. Migration of Implanon ${ }^{\circledR}$. J Fam Plann Reprod Health Care 2006; 32: 157-159.

28 Cozens NJA. Contraceptive implants: high resolution ultrasonography facilitates removal. Br Med J 1996; 313: 880.

29 Evans R, Holman R, Lindsay E. Migration of Implanon ${ }^{\circledR}$ : two case reports. J Fam Plann Reprod Health Care 2005; 31: 71-72.

30 Westerway SC, Picker R, Christie J. Implanon implant detection with ultrasound and magnetic resonance imaging. Aust N Z J Obstet Gynaecol 2003; 43: 346-350.

31 Shulman LP, Gabriel H. Management and localization strategies for the nonpalpable Implanon rod. Contraception 2006; 73: 325-330.

32 Sarma SP, Silverstein M, Lewis C. Removal of a Norplant $\mathbb{R}$ implant located near a major nerve using interventional radiology-digital subtraction fluoroscopy. Contraception 1998; 58: 387-389.

33 Newton MP, Mascarenhas L, Xiao-Feng L, Newton J. Experience with contraceptive implants: removal technique, classification of difficulties and the importance of correct placement. Br J Fam Planning 1995; 21(Suppl.): 14-16.

34 Nelson AL, Sinow RM. Real-time ultrasonographically guided removal of nonpalpable and intramuscular Norplant capsules. Am J Obstet Gynecol 1998; 178: 1185-1193.

35 Mansour D. UK provision for removal of non-palpable contraceptive implants. J Fam Plann Reprod Health Care 2009; 35: 3-4.

36 Faculty of Sexual \& Reproductive Healthcare. For a woman using the etonogestrel implant, Implanon, which has been found to be located in her biceps muscle, should it be removed under local anaesthetic? Members' Enquiry 1766. 20 September 2006. Clinical Effectiveness Unit: on file.

37 James $P$, Trenery J. Ultrasound localisation and removal of non-palpable Implanon implants. Aust N Z J Obstet Gynaecol 2006; 46: 225-228.

38 Vidin E, Garbin O, Rodriguez B, Favre R, Bettahar-Lebugle K. Removal of etonogestrel contraceptive implants in the operating theater: report on 28 cases. Contraception 2007; 76: 35-39.

39 C v Sefton Primary Care Trust Lawtel LTLPI; 24 August 2005.

40 Mansour D, Walling M, Glenn D, Egarter C, Graesslin O, Herbst J, et al. Removal of non-palpable etonogestrel implants. J Fam Plann Reprod Health Care 2008; 34: 89-91.

41 Mourtialon P, Tixier H, Loffroy R, Maillart JC, Calmelet P,
Dellinger $\mathrm{P}$, et al. Vascular complication after insertion of a subcutaneous contraceptive implant. Acta Obstet Gynecol Scand 2008; 87: 1256-1258.

42 Searle ES. Norplant neuropathy [Letter]. Br J Fam Planning 1994; 20: 101

43 Chang A, Edlich RF, Himel HN. Local reactions at the insertion site of the Norplant contraceptive system. J Long Term Eff Med Implants 1993; 3: 305-312.

44 Sarma SP, Hatcher RA. Neurovascular injury during removal of levonorgestrel implants. Am J Obstet Gynecol 1995; 172: 120-121.

45 Arribas-Mir L, Rueda-Lozano D, Agrela-Cardona M, CedeñoBenavides T, Olvera-Porcel C, Bueno-Cavanillas A. Insertion and 3-year follow-up experience of 372 etonogestrel subderma contraceptive implants by family physicians in Granada, Spain. Contraception 2009; 80: 457-462.

46 Nash C, Staunton T. Focal brachial cutaneous neuropathy associated with Norplant ${ }^{\circledR}$ use: suggests careful consideration of the recommended site for inserting contraceptive implants. $J$ Fam Plann Reprod Health Care 2001; 27: 155-156.

47 Wechselberger G, Wolfram D, Pülzl P, Soelder E, Schoeller T. Nerve injury caused by removal of an implantable hormonal contraceptive. Am J Obstet Gynecol 2006; 195: 323-326.

48 Webb AMC. Why go to Tiger Country? A report of two cases of Implanon ${ }^{\circledR}$ removal. J Fam Plann Reprod Health Care 2006; 32: 193-194.

49 Marin R, McMillian D. Ulnar neuropathy associated with subdermal contraceptive implant. South Med J 1998; 91: 875-878.

50 Smith JM, Conwit RA, Blumenthal PD. Ulnar nerve injury associated with removal of Norplant implants. Contraception 1998; 57: 99-101.

51 Osman N, Mirlesse V. A new complication of contraceptive hormonal implant: about two cases of lesions of the ulnar nerve at the arm level [in French]. Gynecol Obstet Fertil 2005; 33: 322-325.

52 Bragg TWH, Jose RM, Bland JW, Matthews RN, Srivastava S. Implantable contraceptive devices: primum non nocere. J Fam Plann Reprod Health Care 2006; 32: 190-192.

53 Anonymous. Nerve damage blamed on contraceptive implant placement. Clinician Reviews 2007; 17: 15.

54 Medicines and Healthcare products Regulatory Agency (MHRA). Download Drug Analysis Prints (DAPs). http://www.mhra.gov.uk/Onlineservices/Medicines/Druganaly sisprints/index.htm [Accessed 22 July 2010].

55 Berner LS. Implants, Norplant: dejà vu all over again. $\checkmark$ Womens Health 1995; 4: 353-355.

\section{NEWS ROUNDUP}

\section{'My Contraception Tool' launched} Sexual health charities Brook and FPA have launched 'My Contraception Tool' (v. 1.0) a web tool designed to support people's contraceptive choices by evaluating their preferences and priorities as well as their physical needs. This new web tool allows patients to search for options in contraception tailored to their needs. The circumstances, medical history and personal preferences are input by the user online. These data are then processed and each contraceptive method is ranked in order to suit individual needs. The results can then be printed and taken to help initiate conversations with a health care professional

The tool is designed for use by men and women of any age who want to use contraception and is linked to further information about each contraceptive method as well as a wealth of information on other aspects of sexual health.

Sources: www.brook.org.uk/mycontraceptiontool and

www.fpa. org.uk/mycontraceptiontool

\section{Study confirms HPV vaccine more} effective than previously thought

Scientists at the Health Protection Agency (HPA), the University of Manchester and the Manchester Royal Infirmary have found that the cervical cancer vaccine could prevent more cases of the disease in England than previously thought, according to a study published in the British Journal of Cancer. This could potentially reduce the annual number of cases from around 3000 to less than 700 .

Cervical cancer is caused by an infection called human papillomavirus (HPV). The study found that $73-77 \%$ of cervical cancer cases were caused by either HPV type 16 or 18 , both of which are prevented by the current vaccine used in the UK. Prior to this study, the available data had suggested $70 \%$ of cases were caused by these types. Current vaccines do not protect against all HPV types that cause cervical cancer, but they do protect against these two most common types.

\section{Reference}

Howell-Jones R, Bailey A, Beddows S, Sargent A, de Silva N, Wilson G, et al.; Study Group Collaborators. Multi-site study of HPV type-specific prevalence in women with cervical cancer, intraepithelial neoplasia and normal cytology, in England. Br J Cancer 2010; 103: $209-216$.

\section{'The Middle-age Spread' \\ (STIs in the over-50s)}

Growth in sexually transmitted infections (STIs) amongst the over-50s has reached alarming proportions. A recent poll by the Royal Pharmaceutical Society of Great Britain found that almost one in five of 45-54-year-olds admitted to having unprotected sex with someone other than a long-term partner. And a further $20 \%$ believed that their chances of picking up an STI were "next to nothing" in these circumstances. A campaign to remind the over-50s that they are at risk from STIs has been launched by sexual health charity, FPA. Entitled 'The Middle-age Spread', the campaign has a message for men and women in that age group who are starting new relationships: "You may not think it applies to you, but if you are having sex with a new partner, you can catch an STI as easily as someone in their 20s".

Source: http://www.fpa.org.uk/Campaignsandadvocacy/Sexual HealthWeek/stisandsafersexover 50

\section{New interactive text messaging} service for young people

Ask Brook has added a text service to its helpline and online service. Young people can text Ask Brook with any question about sexual health or relationships and receive an individual response within one working day. The text number is 07717989023 and all text messages are confidential. Texts will be charged at the young person's standard network rate. Ask Brook Helpline on 08088021234 is available from 9.00am until 7.00pm Monday to Friday.

Source: www.askbrook.org.uk

Reviewed by Henrietta Hughes, MRCGP, DFSRH General Practitioner, London, UK 